\title{
Erratum to: Computational Methods for Elastoplasticity: An Overview of Conventional and Less-Conventional Approaches
}

\author{
Giulia Scalet $^{1} \cdot$ Ferdinando Auricchio $^{1}$
}

Published online: 30 March 2017

(C) CIMNE, Barcelona, Spain 2017

\section{Erratum to: Arch Computat Methods Eng DOI 10.1007/s11831-016-9208-x}

The vendor wrongly numbered the equations in text portions without considering the equations in tables. And ignored and misinterpreted the author corrections.
The original version of this article was revised.

The online version of the original article can be found under doi:10.1007/s11831-016-9208-x.

\section{Giulia Scalet}

giulia.scalet@unipv.it

1 Department of Civil Engineering and Architecture, University of Pavia, via Ferrata 3, 27100 Pavia, Italy
As a result, the referencing in the text to the equations is incorrect. 